\title{
LA GUERRA DE AFRICA (1909) EN LA PRENSA SEVILLANA
}

\author{
$M^{a}$ Dolores López Enamorado \\ Eugenia Gálvez Vázquez
}

\begin{abstract}
El objetivo principal de este trabajo ${ }^{1}$ es el de analizar el papel del pueblo ante situaciones dadas, y cómo éste reacciona ante mensajes recibidos desde distintos ángulos, entre ellos uno importante y concreto: la prensa. Si tomamos como ejemplo la Guerra de Vietnam y su impopularidad de cara al ciudadano medio norteamericano, podríamos pensar que ésta procedía de la pérdida de una serie de valores que habían tenido vigencia en épocas en las que peligraba su país, pero que carecían de esa vigencia cuando dicho país, el suyo, gozaba de paz y prosperidad. Los valores políticos que pueden ser propuestos por las clases dirigentes trascienden a los ciudadanos desprovistos de su valor inicial, y muchas veces el sentido común se impone a los intereses de los gobernantes.
\end{abstract}

La prensa, al ser el vehículo de cultura más directo para llegar al pueblo, utiliza mecanismos diversos, siendo intermediaria entre la maquinaria oficial y los receptores del mensaje, es decir, el pueblo. De este modo, puede jugar un doble papel: el de mero informador de los hechos objetivos, o el de plasmar el sentir del pueblo ante los acontecimientos políticos y sociales. Pero esta labor de intermediario puede llegar al pueblo más o menos mediatizada por las tendencias políticas que defiende o a las que se adscribe un determinado periódico, cuya opinión influirá en el lector que lo adquiera. No obstante, hay un hecho evidente: cuando el bienestar nacional no está en peligro inminente, o cuando la nación se halla en un estado de deterioro en el que cualquier esfuerzo en pro de un prestigio mal interpretado genera más perjuicios que ganancias, entonces resurge en el pueblo ese sexto sentido que se llama cordura.

Por otra parte, y siguiendo con los objetivos de este trabajo, nuestra vida profesional nos ha puesto en contacto con un país, Marruecos, cuyo pasado no tan remoto causó impacto tanto en su población como en la española, y cuyos ecos han llegado hasta nosotros, ya sea de un bando o de otro, sufriendo siempre una distorsión, según sea el emisor que nos transmita las informaciones.

\footnotetext{
${ }^{1}$ Respetaremos en este trabajo el lenguaje utilizado en los periódicos de la época, así como la puntuación, la terminología y las transcripciones, que a veces fluctúan de un diario a otro.
} 
El hecho es que, en uno y otro lado, las campañas de Africa produjeron un trauma difícil de superar, y nos hemos preguntado: ¿cómo se enfrentaron los españoles de aquella época con los hechos consumados? Así, en el presente trabajo ofrecemos los aspectos recogidos en la prensa sevillana de la época, tratando no ya de dar una visión exhaustiva de las diferentes informaciones, sino una aproximación general de la utilización de la información dirigida a las masas. Por otra parte, inmersos ya en el trabajo, nuestro contacto directo con los habitantes de Marruecos, unido a la proximidad geográfica de este país con el nuestro, nos impulsan a no dar por terminada esta línea de investigación limitándonos a la visión española de los hechos, sino que nos gustaría intentar en un futuro cercano una aproximación a dichos acontecimientos desde la óptica marroquí, ya que consideramos que es el único medio, ahora que la perspectiva histórica nos lo permite, de hacer un análisis objetivo desde los diferentes puntos de vista.

Hemos basado nuestro análisis en el material proporcionado por la Hemeroteca de Sevilla, a cuyo director, D. Alfonso Braojos, agradecemos desde aquí las facilidades prestadas para acceder a los fondos documentales.

En el repertorio de la prensa sevillana del año 1909 nos encontramos con que la mayoría de los periódicos recogidos en la Hemeroteca son de matiz independiente o liberal, y así se declaran en sus cabeceras. Hay otros, como El Correo de Andalucía que se declara "Diario católico de noticias", o La Unidad Católica, que se autodenomina "Diario político tradicionalista y antiliberal". A pesar de todo, echamos de menos en este muestreo la prensa de oposición propiamente dicha, es decir, de oposición al Partido Liberal que en estos momentos gobernaba España. El número de títulos no es excesivo en ese año, y muchas veces faltan ejemplares correspondientes no sólo a días sino incluso a semanas o a meses completos. De todos modos, tras revisar toda la prensa a nuestro alcance, hemos optado por reseñar aquí solamente los diarios, y de éstos, los que nos han parecido de mayor relevancia, destacando los siguientes:

-La Andalucía Moderna, Diario independiente, liberal y mercantil. Fundado en 1888. Desparecido en 1911.

- El Correo de Andalucía. Diario católico. Fundado en 1899, y que aún hoy se edita.

- El Heraldo Sevillano. Diario liberal democrático, órgano del Partido Liberal. Fundado en 1877. Desaparecido en 1916.

-El Liberal. Diario liberal. Fundado en 1901. Desaparecido en 1936.

-El Noticiero Sevillano. Diario independiente. Fundado en 1893. Desaparecido en 1933.

- La Unidad Católica. Diario político, tradicionalista y antiliberal. Fundado en 1909. Desaparecido en 1939.

A finales del siglo XIX, España se encuentra ante la pérdida de sus colonias, deshecha espiritual y materialmente, mientras que la expansión europea está tocando a su fin. Pocos territorios quedan ya por colonizar, y difícilmente puede España resarcirse de todas sus pérdidas coloniales. Queda, sin embargo, el sultanato de Marruecos, donde Francia está 
empeñada en una aventura de expansión para consolidar sus dominios desde Argelia hacia el Noroeste de Africa. Y es precisamente ese afán expansionista francés el que va a arrastrar a nuestro país hacia un destino no buscado y de resultados dudosos.

En este sentido, y dentro de la política de penetración pacífica, España va desempeñando una labor cultural al mismo tiempo que divulgativa. En el primer aspecto encontramos hechos acertados, como es, por ejemplo, el de la creación de cátedras de árabe vulgar en las Escuelas de Comercio españolas, con el fin de poner al alcance de la industria, la diplomacia y el propio comercio el cónocimiento de dicha lengua ${ }^{2}$, o la creación de escuelas españolas en Tánger, patrocinadas por el Marqués de Casa Riera, "obra de capital interés para la restauración de nuestra influencia y prestigios no poco decaídos, por causas de todos conocidas en Marruecos"13.

España, por otra parte, se propone a través de la prensa, llevar al conocimiento del pueblo las costumbres y creencias del país colonizado. En este sentido, la prensa que hemos consultado no puede ser más inoportuna e ignorante respecto a tales noticias. De todos los hechos sociológicos o religiosos que se van relatando, no sólo a lo largo de la penetración pacífica, sino también en el transcurso de las campañas, no existe ni una sola nota de rigor científico.

Señalemos en esta primera etapa, en la que todavía no se han enconado los sentimientos, por ejemplo el artículo que el 18 de febrero de 1909 aparece en Andalucía Moderna, firmado por M. Rodríguez de Celis ${ }^{4}$, que habla de forma banal y frívola sobre el "flirteo" de las moras tangerinas ante la afluencia de europeos a esta ciudad. O el suelto que el 2 de mayo publica ese mismo periódico, y que hace referencia a las mujeres del Sultán: "En Tánger Muley Hafid se deshace de una serie de mujeres de su harén, enviándolas a Marrakech", siguiendo a esta noticia un comentario disparatado, carente de todo respeto hacia las costumbres del otro pueblo.

Por otra parte, también se promueven en la Península una serie de actos y conferencias para propiciar al pueblo el conocimiento de los indígenas. Y aquí cabe citar la conferencia que el catedrático de Filosofía de la Universidad de Burdeos, M. Lapie, pronuncia en la Central de Madrid sobre el Norte de Africa. La noticia concluye así:

"La raza musulmana evoluciona y se modifica en sentido progresivo, y esta circunstancia pueden aprovecharla Francia y España mediante una acción fecunda para los intereses de la Humanidad, cumpliendo así la misión histórica que de derecho corresponde a las dos naciones hermanas. ${ }^{5}$

En 1898, con la firma de Tratado de París, España renuncia a intervenir en ninguna aventura colonialista, pues se pensaba que no tendría éxito alguno su intervención en Africa.

\footnotetext{
${ }^{2}$ B. López García, "España en Africa: génesis y significación de la decana de la prensa africanista del siglo XX", Almenara, IV (1973) 46.

${ }^{3}$ Andalucía Moderna, 3 y 5 de enero de 1909.

${ }^{4}$ Se trata de un caso extraño en este periódico, ya que las colaboraciones no suelen ir firmadas.

${ }^{5}$ Andalucía Moderna, 9.2.1909.
} 
Los intelectuales, por su parte, propugnaban una acción que sacase a España de sus fronteras; los políticos de la oposición se inclinaban por un cambio completo de rumbo político; mientras tanto, los anarquistas iban cobrando fuerza, sobre todo en Barcelona. La prensa de este momento, al servicio de los partidos, tendía más a lamentar la situación que a sugerir nuevas directrices.

Pero hay un hecho importante que no se nos oculta a estas alturas, y es que la opinión pública en torno a Africa no existía. El desconocimiento del país, de su lengua, de sus costumbres y de sus creencias era notorio, tanto que es precisamente la prensa la que se va a encargar en los años sucesivos de orientar al pueblo sobre estos aspectos, ofreciéndolos al público lector lamentablemente sesgados y tergiversados en la mayoría de los casos.

España perdió todo el interés por Africa a raíz del descubrimiento de América, dando la espalda a estrechos lazos de cultura común, que se remontaban a épocas muy fructíferas, pero que la política imperialista y las cuestiones religiosas los habían hecho desaparecer de los programas políticos. Al volver la cara de nuevo hacia Africa, tras la pérdida de las colonias americanas, en un estado de desastre total y arrastrada por las ambiciones colonialistas de Francia, España se encontraba inerme ante una potencia que se había empeñado en una conquista provista de una preparación intelecual y una conciencia política de la que España carecía.

Tras un largo tira y afloja de tratados y ententes, y a pesar de la pasividad de su gobierno, España se ve sentada ante la mesa de negociaciones, con la celebración de la Conferencia de Algeciras (enero-abril de 1906). En ella se estudiaron las reformas a introducir en el imperio de Marruecos "sobre la base del triple principio de la soberanía del sultán, integridad de su estado y régimen de puerta abierta en materia comercial."6

Marruecos, por su parte, vive una situación interna crucial, con un sultanato tambaleante que se debate entre tres pretendientes al poder: Mulley Abd el-Aziz, que había subido al trono en 1895, siendo derrocado en 1907. Sobre este sultán hay unas noticias curiosas en las que se destaca que dicho personaje pretende recuperar el trono, y para ello intenta ganarse a las gentes de relieve político dando grandes fiestas y ejerciendo el mecenazgo sobre algunos artistas ${ }^{7}$. Esta noticia se completa con una pequeña nota en la que se refiere la adquisición por parte de Muley Abd el-Aziz de un terreno para vivir, en las cercanías de Tánger ${ }^{8}$. Por otra parte, y según se desprende de unas noticias aparecidas en enero de $1909^{9}$, la familia real española matuvo una relación de amistad con el sultán destronado, ya que en dichas informaciones se reseña la visita al mismo del príncipe D. Jaime de Borbón. En Andalucía Moderna se dice textualmente:

\footnotetext{
6 T. García Figueras, La acción africana en España en torno al 98 (1860-1912), tomo II (Madrid 1966) 13.

${ }^{7}$ Andalucía Moderna, 22.1.1909.

${ }^{8}$ La Unidad Católica, 8.2.1909 y El Correo de Andalucía, 7.2.1909.

${ }^{9}$ La Unidad Católica, 28.1.1909 y Andalucía Moderna, 30.1.1909.
} 
"Hablaron naturalmente de la situación de España y coincidieron en estimarla mediana. Abd al-Aziz se mostró disgustado de la conducta que con él habían observado los españoles, y D. Jaime no se mostró satisfecho."10

Esta noticia llega al periódico a través de la nota enviada por un miembro vasco del séquito que acompaña a D. Jaime en su viaje a Marruecos.

El Roghi, que alegaba sus derechos a la sucesión por ser hijo de un antiguo gobernante destronado. Se establece en el Rif en una actitud de rebeldía contra el sultán, que difícilmente podía controlar la situación, teniendo también España las manos atadas, ya que estaba comprometida a apoyar al primero en cumplimiento de los acuerdos de 1904.

La trayectoria de El Roghi puede ser seguida paso a paso en la prensa que hemos manejado, a través de breves comunicados. Su final, conocido de todos por sus trágicas circunstancias, tuvo lugar en agosto de 1909. Es El Correo de Andalucía el que con más detalle cita los enfrentamienros entre los partidarios de El Roghi y las mehallas del sultán.

Muley Hafid, sultán reinante desde 1907, año en el que su pueblo había derrocado a su hermano Muley Abd al-Aziz, proclamando a éste como su sucesor, aunque no sería reconocido por las potencias extranjeras hasta enero de $1909^{11}$.

El Roghi había pactado con una compañía francesa vendiéndole unos derechos mineros, y con la Compañía Española de las Minas del Rif -fundada poco antes- para la explotación de otros yacimientos al suroeste de Melilla. España por tanto se encuentra de un lado comprometida, como hemos mencionado, con el sultán, y por otro empeñada en proteger los negocios de una serie de particulares españoles que tenían allí sus intereses, entre otros en conde de Romanones.

Paralela a esta componenda política, surge en la población marroquí un ansia de pureza religiosa inspirada e impulsada por una serie de personajes religiosos que, con el pretexto de salvaguardar su credo de influencias extrañas, avivan el fuego de la guerra santa. Esta animadversión contra el intrusismo, provocada por los avances franceses, se hace extensiva a los extranjeros en general.

A su vez el Gobierno español, fiel a sus tratados, envía a Fez, en febrero de 1909, a Merry del Val como embajador de España, pero sus negociaciones no llegan a buen fin. La salida de España de esta embajada está consignada el 25 de febrero, y pocos días después se recoge con bastantes detalles la salida de Tánger camino de Fez, la capital del imperio marroquí que, "a pesar de no hallarse nada más que a 260 km de Europa, está más aislada que cualquier ciudad del Extremo Oriente."12 Hace un alto en Alcazarquivir, única ciudad que se

\footnotetext{
$10 \mathrm{Ib}$.

11 T. Ruiz de Cuevas, Apuntes para la historia política de Africa, vol. I, tomo I: Marruecos (Madrid 1971) 64.

12 Andalucía Moderna, 6.3.1909.
} 
encuentra en el trayecto, y tras un viaje muy fatigoso es recibida fastuosamente. ${ }^{13} \mathrm{El} 22 \mathrm{de}$ marzo de 1909 tendría lugar la presentación de credenciales. ${ }^{14}$

Por esos mismo días el Rey -que está en Algeciras camino de Ceuta, donde llega el 9 de marzo de 1909- se reúne con "moros notables, afectos a España que se le muestran ansiosos de gozar de su soberanía", según se recoge en Andalucía Moderna. Ese mismo diario publica el 11 de marzo un editorial comentando el viaje del rey a Ceuta, y la decadencia total de la dominación española en Africa. España se ha dejado arrebatar su influencia por potencias como Francia y Alemania. Sólo queda Ceuta, convertida en presidio, y las obras de mejora se hacen lentamente. Encomia este periódico la iniciativa de Alfonso XIII que, contra "todas las trabas de la etiqueta y de la diplomacia, se siente hombre de su tiempo (...) abandonando el territorio peninsular para conocer nuestras poblaciones africanas." 15

La actitud pesimista de este periódico sobre la acción española en Marruecos se plasma también en un artículo del 2 de abril de 1909 sobre la ciudad de Fez y su comercio. En él se hace una enumeración de los productos que se venden en sus mercados, y termina: "Francia, Inglaterra y Alemania, son, pues, las tres naciones que hacen el comercio en Fez. España envía tan poco que apenas tiene mercado."

Uno de los momentos más tensos en esta etapa de las relaciones entre España y Marruecos es el de la fallida misión del embajador Merry del Val ante la intransigencia del sultán, que comunica al rey Alfonso XIII su decisión de enviar por su parte una embajada a Madrid "que trate directamente con el Gobierno las cuestiones que han originado la referida disconformidad, especialmente las que hacen relación a los territorios del Riff y Cabo de Agua." ${ }^{16}$ En este mismo sentido se expresa Andalucía Moderna el 10 y 12 de mayo de 1909, diciendo que Muley Hafid exige la promesa de que sean evacuadas las posiciones que guarnecen Cabo de Agua y Mar Chica. Añade asímismo que el sultán se niega a hablar de otros asuntos hasta que no se resuelva éste. España, aun sabiendo que el trámite de enviar una embajada a Madrid es desusado, está dispuesta a recibirla a condición de que, con anterioridad, se hayan tratado los asuntos pendientes. En ese sentido, aparece en la prensa una escueta y significativa noticia, que dice textualmente:

"Circulan rumores alarmantes acerca del envío de tropas a Marruecos."17

En este momento, la opinión general es consciente de enfrentarse a graves acontecimientos. El asunto de Marruecos es debatido en el Congreso y en el Senado, y repercute negativamente en la Bolsa, que se recupera al saberse que los sucesos de Marruecos afectan por igual a Francia e Inglaterra. ${ }^{18}$

\footnotetext{
${ }^{13}$ El Correo de Andalucía, 12.3.1909.

${ }^{14}$ Andalucía Moderna, 23.3.1909. El Correo de Andalucía del 22.3.1909 añade que en ese acto se estableció el compromiso de respetar el Acta de Algeciras.

15 Andalucía Moderna, 11.3.1909.

${ }^{16}$ El Correo de Andalucía, 10.5.1909.

17 Andalucía Moderna, 12.5.1909.

${ }^{18}$ El Correo de Andalucía, 12.5.1909.
} 
Tanto El Correo de Andalucía (12.5.1909) como Andalucía Moderna (14.5.1909) recogen y glosan el editorial del órgano monárquico de Madrid La Correspondencia de España, del 12 de mayo de 1909, cuyo autor es Rodríguez de Celis, cronista de esa embajada española. Es digno destacar la impotencia y el pesimismo que rezuman ambos comentarios. El Correo de Andalucía, sin embargo, anima a la opinión pública diciendo:

"Si el Gobierno no se decide a desarrollar en Marruecos una enérgica acción militar, se esfumará y perderá por entero el porvenir de España en el vecino continente."

Andalucía Moderna arremete contra los manejos de los moros, su marrullería y su eterna desconfianza, "falsamente humildes, hipócritamente confusos, baja la cabeza, cruzados los brazos, exclamando en el momento de las resoluciones decisivas: ¡No entendemos! ¡No comprendemos el asunto! ¡Necesitamos meditar!"

Ambos comentaristas ven en la actitud del sultán la mano de Francia, y temen que éste haya sacado la conclusión de "que somos pobres, viciosos, degenerados, país sin Ejército, nación sin Marina, pueblo sin bríos, incapaz de un intento de demostración armada ni siquiera para defender y conservar nuestra zona de influencia en el territorio marroquí." ${ }^{19}$ En este sentido, las noticias y comentarios se suceden. La reacción ante el fracaso de la embajada de Merry del Val tiene amplio eco, y de todos los comentarios publicados en la prensa sevillana de esos días se desprende un sentimiento de inferioridad ante la mano oculta de las potencias, así como un deseo de demostrar al gobierno marroquí hasta donde pueden llegar los españoles. Entresacamos algunos párrafos de El Correo de Andalucía, del día 14 de mayo, que, junto con lo que anteriomente hemos comentado, dan idea de la situación de impotencia en la que España se encuentra:

"El sultán ha dado á los nuestros con la puerta en las narices, pidiéndoles que abandonemos lo poco que en Marruecos teníamos. (...) está bien que se discuta sobre si nos convendrá ahora meternos en algún lío internacional y enseñar los dientes á la morisma, para que vean que no estamos gallinas sino farrucos, ó si habremos de resignarnos á nuestra suerte perra, despidiéndonos para siempre de Marruecos."

Ya tensos los ánimos con este fracaso, la ruptura de la penetración pacífica española puede datarse en julio de 1909, mes en el que se produce la agresión a los obreros que trabajaban en el tendido de ferrocarril de Melilla a las minas, con la muerte de nueve de ellos:

"La muerte de los obreros españoles no es un accidente fortuíto -comentaba el sultán Muley Hafid, recién ocurridos los sucesos desencadenantes del aciago episodio- (...) Los españoles llevaban a cabo la preparación militar desde hace dos meses sin estar amenazados, y realizaban obras públicas en territorio marroquí; era evidente que esas obras efectuadas en una región insumisa (...) debían conducir fatalmente a estos incidentes previstos de antemano." 20

\footnotetext{
19 Andalucía Moderna, 14.5.1909.

20 Se trata de una conversación mantenida entre Muley Hafid y Henri Galliard en Fez, el 19 de julio de 1909. Cfr.: V. Morales Lezcano, El colonialismo hispano-francés en Marruecos (1898-1927) (Madrid 1976) 34.
} 
A raiz de estos sucesos, Maura, a la cabeza del gobierno español, da órdenes al Comandante Militar de Melilla, general Marina, para que se tomen las medidas oportunas a fin de proteger a los mineros. La acción del general Marina fue fortificar la zona e intentar poner orden, dispersando a los agresores. Pero el territorio era demasiado extenso, y se temía que a estos primeros agresores se unieran nuevas kabilas de la zona -como efectivamente ocurriría más tarde-.

Esto provoca una obligada movilización de tropas de las que la mayoría eran reservistas, y algunos sin entrenamiento militar desde hacía varios años. Dado que estos soldados no percibían salario alguno, las familias quedaban desasistidas con su marcha. Las movilizaciones se llevaron a cabo casi en su mayoría en las zonas urbanas, con el pretexto de que resultaba más fácil reclutar allí a este tipo de tropas. Pero entre los soldados estaba arraigando la idea de que ellos no iban a Africa a defender a la Patria, sino a defender los intereses económicos de unos cuantos, y a facilitar la promoción de los oficiales del Ejército.

El desencanto popular llegó a ser tan grande que el comentario del mismo trascendió al público no por los medios de comunicación izquierdistas o progresistas, sino por el órgano monárquico de Madrid, La Correspondencia de España, que el 12 de julio de 1909 declaraba:

"Es imposible llevar adelante una guerra si el pueblo no la quiere, y el pueblo español no quiere ni oír hablar de combatir en Marruecos. A excepción de una media docena de caballeros políticos, de unos pocos especuladores del mercado, y de otros pescadores en río revuelto, nadie quiere aventuras, ni provocaciones, ni ocupaciones innecesarias ni ningún tipo de empresas extemporáneas o innecesarias. Si España hubiera llevado algo a cabo en Fernando Poo y El Muni, y si el país supiera que iban a resolver algún problema en Marruecos, podría tolerar una política imperialista, pero como se ve que vamos á Marruecos sin saber cómo ni porqué, no apoya la empresa.

Supongamos que nuestras tropas salen de Melilla y ocupan 10, 20, 30 ó 100 kilómetros. Y bien, están ocupados. ¿Y con qué propósito? Con ninguno. Absolutamente ninguno como no sea el de gastar cien millones o más de pesetas que tanta falta hacen en casa y que en Marruecos no sirven á ningún propósito. Varios cientos de soldados morirían, muchos otros serían promovidos, una vez más mostraríamos nuestra falta de organización y nos pondríamos en ridículo por centésima vez llamando a unas cuantas balas perdidas una escaramuza, a una escaramuza una empresa militar, a una expedición de reconocimiento un combate, y a un combate una batalla campal. Mandaríamos más generales que coroneles, más oficiales que tenientes, más tenientes que soldados, más promesas que realidades, y más proyectos que hechos. Lo que es más, por todos nuestros esfuerzos sólo conseguiríamos una cosa: Malgastar la sangre de los soldados y el dinero de los contribuyentes.

¿A qué seguir mintiendo si ésta es la verdad? ¿Por qué propagar ridículas ilusiones si las cosas son lo que son y no lo que queremos que sean?...

Ni el Gobierno ni el Rey deben olvidarlo: ir á Marruecos será mil veces más peligroso que no ir (...) y al decirlo sirvo mejor á la patria y al Rey que si pretendiera que yendo a Marruecos se servirán los intereses de la nación y de la monarquía."21

21 S. Payne, Ejército y sociedad en la España liberal (1808-1936) (Madrid 1977) 159-161. 
El marcado antimilitarismo provocado por la movilización de los reservistas tuvo una serie de consecuencias que culminaron en julio con los sucesos de Barcelona, cuya población, apoyándose en fuerzas anarquistas anticlericales, salió a la calle dando lugar a los sangrientos sucesos conocidos como la Semana Trágica, siendo Ferrer, el director de la Escuela Moderna, su chivo expiatorio. Estos desafortunados acontecimientos acarrearon sobre España una dura campaña internacional de desprestigio.

Entretanto las fuerzas españolas seguían siendo hostigadas. El 24 de julio se enviaron varias unidades con el objetivo de ocupar las vías de acceso al Monte Gurugú, próximo a Melilla. Estas operaciones produjeron gran desconcierto para los militares españoles, que desconocían el terreno, careciendo de mapas y de orientación sobre la zona. Se sucedían emboscadas y bajas. El 25 de julio llegan 17.000 soldados a Melilla, y el 27 tiene lugar el desastre del Barranco del Lobo, en el que las tropas españolas, haciendo caso omiso a las instrucciones, cayeron en una emboscada. El general Marina pidió refuerzos y, a finales de septiembre, las fuerzas españolas destacadas en Melilla alcanzaban el número de 40.000. El único triunfo que se pudo reseñar fue la toma de la kabila de Qebdana. ${ }^{22}$

Desgraciadamente, salvo en El Correo de Andalucía, en el resto de la prensa consultada faltan los ejemplares de estos meses centrales del año 1909. Este periódico por su parte ofrece una serie de noticias puntuales, resaltando el valor de los soldados españoles, y el arrojo y fiereza de las tropas marroquíes, superiores con mucho en número. Del mismo modo, es posible seguir las diferentes dudas planteadas sobre la conveniencia o no de entrar en la guerra, cuando ya se están haciendo maniobras preparatorias en Melilla. Espigando entre las diversas opiniones y noticias, hemos seleccionado el siguiente fragmento:

"Vamos a Marruecos á sacarles á los europeos las castañas del fuego con el famoso régimen de puerta abierta.

$$
\text { (...) }
$$

El conde de Romanones, que aspira á ser y lo será dentro de poco uno de los mayores ricos de Europa, buscó y explotó en Marruecos unas minas, las de Beni-Bu-Frur..."23

Continúa diciendo que los soldados españoles no protegieron estas minas, y sin embargo ahora que los franceses piden ese auxilio, España va a defenderlos, azuzada por Francia. "Es decir, que para que un extranjero explote un negocio y haga fortuna, nosotros vamos á llevar á Marruecos millones y soldados, á tirar cañonazos, á matar gente y á dejar que nos maten a nosotros. Nosotros guerreamos por las minas del prójimo. ¿No es esto llevar la cesta?"24

Según va transcurriendo el verano, la opinión pública va cambiando, inclinándose hasta seguir "con patriótico interés y con inequívocas muestras de cariño, la acción de nuestras tropas". 25

\footnotetext{
22 S. Payne, op. cit., 165.

23 El título de este artículo es ya de por sí expresivo: "España llevando la cesta", El Correo de Andalucía, 17.6.1909.

$24 \mathrm{Ib}$.

25 T. García Figueras, op. cit, 326.
} 
La Unidad Católica reanuda sus informaciones con la descripción detallada del combate del Zoco el-Arba, que había tenido lugar el 31 de agosto de 1909. En estas descripciones abunda la exaltación del soldado español, frente a un ejército moro muy superior en número, que "parece, visto sin gemelos, un ejército de fantasmas." A pesar de todo "los moros son barridos (...), huyen (...), y queda la llanura sembrada de cadáveres moros." 26 Se destacan también hechos aislados de jóvenes oficiales que realizan acciones heroicas contra el enemigo. La exaltación que produjo esta victoria queda recogida con las siguientes palabras:

"El enemigo acababa de dar muestra de una osadía extraordinaria; pero los proyectiles de los Schneider abatieron sus ímpetus. Dieron, por su parte, nuestras tropas admirables muestras de serenidad, así como tuvieron rasgos de valentía insuperables. (...) Todos nuestros soldados afirman que los moros, en el curso del combate, tuvieron muy mala puntería. (...) Todos nos maravillamos de la suerte que acompaña á las tropas de que es jefe el general Aguilera; buena fortuna que comenzó á demostrarse desde el punto y hora en que llegó a apoderarse del Zoco el-Arba."27

Siguen en este periódico descripciones de la zona con el fin de informar al pueblo del escenario en que se están desarrollando las acciones. ${ }^{28}$

El Heraldo Sevillano, consecuente con esta nueva óptica con la que el pueblo español contempla la guerra de Melilla, publica un artículo de casi dos columnas en el que intenta mostrar los aspectos positivos que pueden tener los "indígenas", dado que ya se ve con buenos ojos el que España colonice este territorio. Este artículo está lleno de tópicos y de lugares comunes. Dice, por ejemplo: "Toda la instrucción de la infancia se resume a aprender el Corán o libro sagrado de Mahoma. (...) Los rifeños son valientes y guerreros y su ocupación principal es el robo, la caza y la piratería."29

Datos a los que se suman otra serie de referencias a los banquetes, la indumentaria y los hombres y mujeres de la zona.

Cuando España va tomando posiciones, el sultán envía una nota a las potencias extranjeras comunicando la actividad española en el Rif, nota a la que la prensa extranjera coincide en no dar valor, al menos aparentemente:

"España está defendiendo en el Riff su honor nacional, Europa confiada en que cumplirá fielmente con sus compromisos internacionales, sigue con tanta simpatía como atención el desarrollo de la acción que ha emprendido, y sólo puede formular votos por el feliz éxito de las armas españolas, puesto que, al fin y al cabo, España está peleando por la causa de la civilización." ${ }^{30}$

\footnotetext{
${ }^{26}$ La Unidad Católica, 3.9.1909.

27 La Unidad Católica, 4.9.1909.

28 Algunos de estos artículos, aparecidos en La Unidad Católica y que recogen diversos aspectos de la geografía y las costumbres de la zona, son: "Quebdana" y "Las Islas Chafarinas" (5.9.1909), "Las riquezas del Riff" (8.9.1909), "Lo que es un zoco" (25.9.1909), "Lo que es la cabila" (26.9.1909), "Las minas del Riff" (21.10.1909).

${ }^{29}$ Este artículo está firmado por el presbítero Cristóbal Jurado, y apareció en El Heraldo Sevillano el 10.9.1909.

${ }^{30}$ La Unidad Católica, 25.9.1909, recogiendo la opinión de Le Journal des Débats.
} 
El siguiente logro importante es la toma del Gurugú, que tiene lugar el 29 de septiembre de 1909, a las 7'55 de la mañana. En este sentido, llueven editoriales, artículos y noticias desbordantes de orgullo y entusiasmo patriótico. El entonces coronel Primo de Rivera estaba al mando de las tropas. La Unidad Católica, en un encendido artículo titulado "¡Viva España!", y aparecido el 30 de septiembre de ese año, comenta:

"La felina astucia de los tigres africanos ha sido, una vez más, humillada bajo la noble y potente garra del león español, que injustamente provocado, rugiente y fiero los hace huir en vergonzosa y precipitada fuga como manada de tímidas gacelas, arrancándoles con el Gurugú, que neciamente creyeron ser inexpugnable baluarte de su alevosía y bárbara crueldad, todas sus esperanzas."

El artículo concluye con vivas a España y al Ejército español.

En un principio la ocupación del Gurugú supuso el hecho moral de izar la bandera española en esa cumbre inaccesible, y de impedir, mediante la toma de esa posición, que los moros atacasen a los convoyes de abastecimientos del ejército. Sobre dicho acto, La Unidad Católica recoge las siguientes palabras del general Del Real:

"iSoldados! Ya ondea la hermosa bandera de la patria en el hasta ahora inexpugnable Gurugú, último refugio de la morisma infiel, y queda elevada á las alturas por los robustos brazos de los hijos de la patria, de los hijos amados del ejército español, que ha vertido pródigamente raudales de sangre. Con sangre se conquistan las glorias. Con sangre se lavan los agravios inferidos á la patria. Soldados: ¡Viva España! ¡Viva el Rey!"31

El día 2 de octubre aparece un editorial ${ }^{32}$ en el que se dice que los españoles "continuarán su marcha triunfando hasta sojuzgar las kabilas que hostilizan á Alhucemas y las que tirotean á diario el Peñón de Vélez hasta llegar a darse la mano con nuestras fuerzas en Ceuta, para que llegue a ser un hecho positivo la libre navegación desde el Muluya á Tánger." Añade a continuación que la labor de pacificación es importantísima porque favorecería una emigración como "a la propia casa" y podría "dar salida a nuestras industrias", así como mantener a raya a los grupos rebeldes y "contra las algaradas que pudieren promover los naturales, dejándose llevar de su genio tan indómito como independiente." También, añade, "podría ser que los reservistas, llevándoles a sus mujeres e hijos, quisieran asentarse en aquellas tierras, y que los andaluces las considerasen como medio natural de expansión (...). Después de la acción militar y gubernamental queda mucho que hacer a la iniciativa privada."

Estas campañas del año 1909 finalizan con el combate y toma de Beni-Bu-Frur y el Zoco el-Jemis, último objetivo del general Marina. La prensa destaca una vez más "el heroísmo de la tropa y el valor salvaje de los moros (...) que continuaban luchando con gran valor despreciando las granadas y los disparos de seis batallones de Cazadores." 33

\footnotetext{
${ }^{31}$ La Unidad Católica, 1.10.1909.

32 "Después de la victoria", Andalucía Moderna, 2.10.1909.

33 Andalucía Moderna, 3.10.1909.
} 
En lo que resta de año, la prensa sevillana seguirá ocupándose de los sucesos de Marruecos, en dos líneas principales:

-Sumisión progresiva de las kabilas rebeldes.

-Relación retrospectiva de hechos gloriosos, individuales o colectivos, de las tropas españolas.

Por otra parte, El Heraldo Sevillano empieza a publicar una serie de artículos en los que se pondera la riqueza poco aprovechada de Marruecos, la feracidad de sus campos, las posibilidades del comercio, etc.

A principios de diciembre se recogen banquetes y actos celebrando el exitoso final de la campaña ${ }^{34}$, que ya el general Marina había adelantado en noviembre:

"(...) siendo el principal objetivo de esta campaña prevenirse de las agresiones que pudieran efectuar los rifeños en la plaza de Melilla, y llevar con esto la tranquilidad al vecindario, y habiéndose cumplido ya ese programa, creo que la campaña ha terminado (...). Hay que evitar las exacerbaciones de odio y pasiones que lejos de provecho, convertirían a la lucha en un mal crónico." 35

El 18 de diciembre, el general Marina publicaba la siguiente Orden de la Plaza:

"Concluído el periodo activo de la campaña que hemos sostenido con algunas cabilas, mañana empezará, por orden superior, el regreso a la Península de la tercera Brigada Mixta, a la que seguirá el Regimiento de Lanceros de la Reina." 36

El 27 de diciembre aparece el siguiente artículo, en que se ofrece una especie de decálogo para el buen entendimiento entre colonizadores y colonizados, que en resumen dice así:

1.- Desechar la idea de que el moro es un enemigo.

2.- Rectificar el error de que el moro es bárbaro y hacer valer sus virtudes.

3.- Los españoles han de aprender a comportarse correctamente en Marruecos, y para ello que copien a los moros que son maestros de corrección sobre todo en lo que atañe a la mujer.

4.- Asegurar la paz de los territorios.

5.- Tratar al indígena como un hermano menor, y corregirlo pero sin odio.

6.- Transformar la policía indígena en ejército colonial.

7.- Estudiar el clima, el suelo y el subsuelo.

8.- Conocer la organización de la propiedad indígena.

9.- Construir puertos y ferrocarriles lo antes posible.

10.- Crear el instrumento administrativo y de gobierno que ha de funcionar en Africa. ${ }^{37}$

El sentir popular quedaría reflejado en canciones y poemas sobre esta acción bélica española que tantos sinsabores trajo, y tan encontrados sentimientos removió:

\footnotetext{
${ }^{34}$ La Unidad Católica, 6.12.1909.

35 La Unidad Católica, 8.11.1909.

36 T. García Figueras, op. cit., 327-328.

37 Gonzalo de Reparaz, "Acción africanista", El Heraldo Sevillano, 27.12.1909.
} 
"Esta carta hacia Melilla en pos del viento llevar para luego ahí entregar á un soldado de Castilla hijo de esta noble villa donde nació aquel gran Goya número seis de Saboya á José Roulet buscar y seguro es de encontrar combatiendo a la jarcoya. P.D.: Olvidado en un renglón las señas que yo tenía son: Primer Batallón y Segunda Compañía."38

O este otro poema titulado "A la Purísima Concepción", del que extractamos lo siguiente:

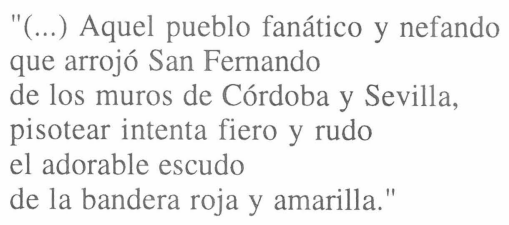

Que termina diciendo:

¡Haz rodar con tu pie la media luna!

¡Haz que triunfe la cruz eternamente!"39

O, para terminar, la canción que ha quedado en la memoria popular:

"En el Barranco del Lobo

hay una fuente que mana sangre de los españoles que murieron por España. Que pobrecitas madres, que cómo llorarán al ver que sus hijos a la guerra van.

$\mathrm{Ni}$ me lavo ni me peino ni me pongo la mantilla hasta que venga mi novio de la guerra de Melilla."

38 Se trata de una carta que lleva en el sobre este poema. La Unidad Católica, 12.9.1909.

${ }^{39}$ La Unidad Católica, 9.11.1909. 
$\cdots, \cdots$ 